\title{
Correction to: Apoptosis of murine melanoma B16-BL6 cells induced by quercetin targeting mitochondria, inhibiting expression of PKC-a and translocating PKC- $\delta$
}

\author{
Xian-Ming Zhang ${ }^{1} \cdot$ Jia Chen $^{1} \cdot$ Yu-Gui Xia ${ }^{1} \cdot$ Qiang Xu ${ }^{1}$
}

Published online: 28 April 2021

๑) Springer-Verlag GmbH Germany, part of Springer Nature 2021

\section{Correction to:}

Cancer Chemother Pharmacol (2005) 55: 251-262

https://doi.org/10.1007/s00280-004-0863-5

In the original publication of the article, there were several inadvertent errors in the Fig. 9a, b and Fig. 10c, d. The corrected Figs. 9 and 10 are given below.

The original article can be found online at https://doi.org/10.1007/ s00280-004-0863-5.

Qiang Xu

molpharm@163.com

1 State Key Laboratory of Pharmaceutical Biotechnology,

School of Life Sciences, Nanjing University,

Nanjing 210093, People's Republic of China 
A

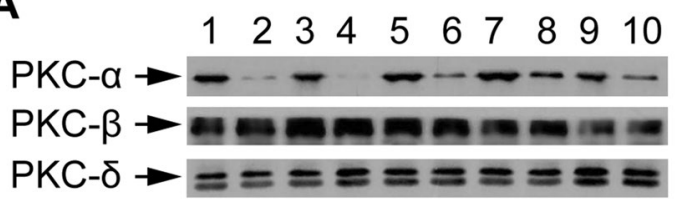

B

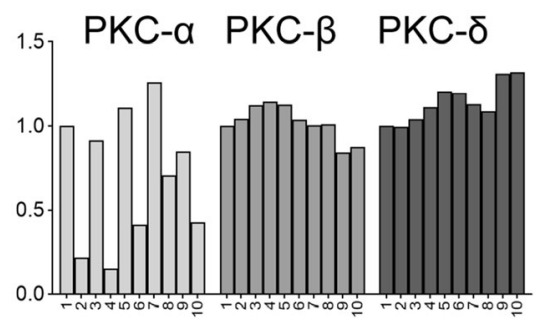

Fig. 9 Effects of PKC activators and inhibitors on the quercetin induced decrease in expression of PKC- $\alpha$. B16-BL6 cells were incubated with quercetin alone or PMA $(100 \mathrm{nM})$, FFA $(6.7 \mathrm{mM})$, doxorubicin $(8.6 \mu \mathrm{M})$ and chlorpromazine $(14 \mathrm{mM})$ in the presence or absence of quercetin for $24 \mathrm{~h}$. a The levels of expression of PKC- $\alpha$, PKC- $\beta$, and PKC- $\delta$ were determined by Western blotting (lane 1 control, lane 2 quercetin alone, lane $3 \mathrm{PMA}$, lane 4 quercetin + PMA, lane 5 FFA, lane 6 quercetin+FFA, lane 7 doxorubicin, lane 8 quercetin+doxorubicin, lane 9 chlorpromazine, lane 10 quercetin + chlorpromazine. b The relative expression of PKC- $\alpha$, PKC- $\beta$, and PKC- $\delta$ in B16-BL6 cells was quantified densitometrically using the software Image $\mathbf{J}$ and calculated according to the reference bands of the control. The data presented are representative of three independent experiments

Publisher's Note Springer Nature remains neutral with regard to jurisdictional claims in published maps and institutional affiliations.

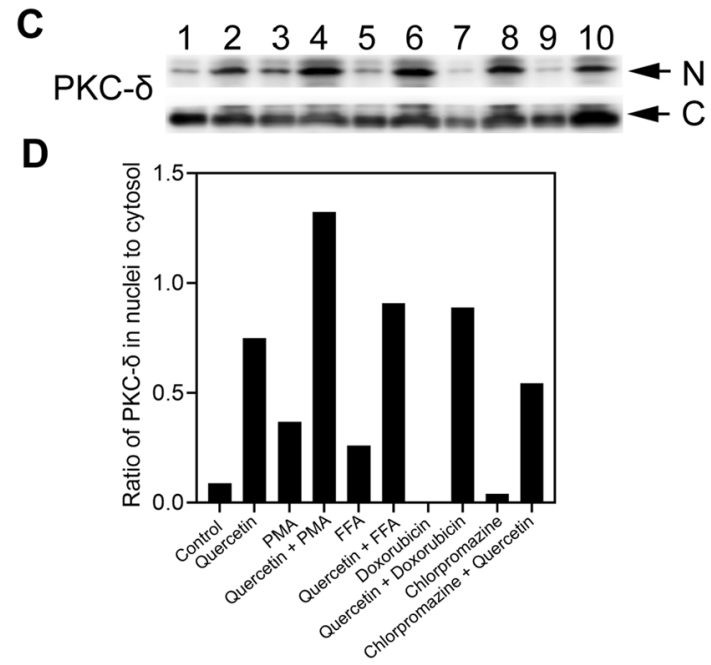

Fig. 10 c Effects of PKC activators and inhibitors on the translocation of PKC- $\delta$ from cytosol to nuclei induced by quercetin. The levels of PKC- $\delta$ in cytosol and nuclei were detected by Western blotting, respectively (lane 1 control, lane 2 quercetin alone, lane $3 \mathrm{PMA}$, lane 4 quercetin + PMA, lane 5 FFA, lane 6 quercetin + FFA, lane 7 doxorubicin, lane 8 quercetin + doxorubicin, lane 9 chlorpromazine, lane 10 quercetin + chlorpromazine). d The ratio of $\mathrm{PKC}-\delta$ in cytosol to nuclei. The relative levels of PKC- $\delta$ in cytosol and nuclei were quantified densitometrically using the software Image $\mathrm{J}$, and calculated according to the reference bands of the control. The data presented are representative of three independent experiments 